\title{
Fertility Trends in Sweden
}

\author{
By EVA M. BERNHARDT and BRITTA HOLMBECK
}

\section{Introduction}

This paper will discuss briefly recent changes in the fertility situation in Sweden with particular attention paid to the frequency of extra-marital births and abortions which have shown rather dramatic increases in recent years. The analysis will cover the years 1960-1972 with the emphasis on the last four years. (The figures for 1972 are preliminary.) The gross reproduction rate has varied in this period from a high of 1.21 in 1964 to a low of 0.94 in 1969 . Within these rather moderate variations, however, there have been significant changes in the ways in which this total fertility level is achieved.

\section{Total Fertility - Trends Since 1960 in Age-specific Rates}

Age-specific rates for five-year age groups are shown in Figure 1 for total fertility (that is, births per 1000 women regardless of marital status). We can distinguish three different patterns with regard to trends in total fertility. For women over 30 the trend has been generally downward with practically no fluctuations. While women in these ages contributed close to 30 per cent of all births in the first half of the 1960's, only one in five of the children born in the early 1970's had a mother of age 30 or over. There is nothing to indicate a reversal of this downward trend; eventually, however, the rates may stabilize at some rather low level.

The second distinct pattern is that for very young women, who experienced a substantial increase in fertility in the middle of the 1960's. From rates around 35 per 1000 there was a rapid increase in the first half of the 1960 's, reaching a peak of 50 per 1000 in 1966 . Thereafter there has been an equally rapid decline, stabilizing at roughly 35 per 1000 in the early 1970 's, that is at about the same level as before. This development is indeed rather remarkable and we shall speculate a little about possible explanations for these trends after having looked at the trends in marital and extra-marital fertility and changes in the marriage pattern and the frequency of abortions.

The third and last category with regard to fertility trends in the 1960 's comprises women in the prime child-bearing ages, that is between 20 and 30 . They participated in the fertility increase in the early 1960 's, reaching peak rates 
Figure 1. Agespecific fertility rates $1960-1972$.

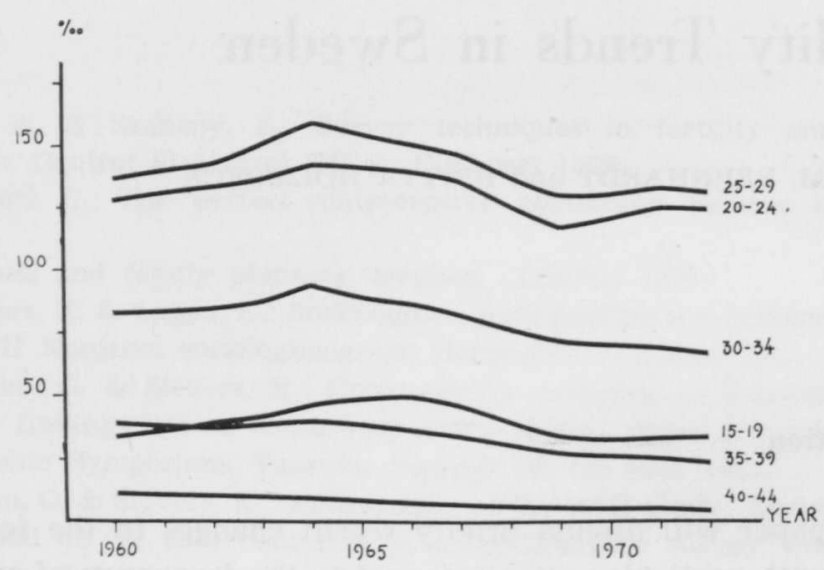

in 1964. After that fertility in these age groups has declined substantially with a slight recovery in the early 1970's, when the rates, however, were still somewhat below those around 1960. Despite that, women in their twenties account for an increasing proportion of the total number of births. The concentration of child-bearing to these age groups is demonstrated by the fact that slightly less than 60 per cent of the births in the $1961-65$ period were to women in the $20-29$ age groups, while this proportion had grown to 70 per cent in the early 1970's.

\section{Marital and Extra-marital Fertility - Trends Since 1960 in Age-specific Rates}

Births occur both within and outside marriage. In Sweden a rather substantial proportion of total births has always occurred to non-married women. In the early 1960's this proportion slightly exceeded 10 per cent. One of the most significant changes in the fertility pattern in the 1960 's is the rather dramatic increase in extra-marital fertility during the second half of the 1960's and the early 1970's, leading to the situation where one in four births occur to women who are not married (1972). In no age group do we find less than 9 per cent extra-marital births. The highest proportion is of course in the youngest age group (15-19), where at present four out of five births occur outside marriage, thus being the rule rather than the exception.

Part of the reason for this increase in extra-marital fertility is the declining propensity to marry. The changes in the marriage pattern, will, however, be dealt with below.

Concomitant with an increase in the proportion of non-married women, especially at ages under 30 , we find, however, a substantial increase in the frequency of child-bearing among non-married women. The number of extramarital births per 1000 non-married women is shown in Figure 2. At all ages, 
that is even for women over 30, the rates are higher in the early 1970's than in 1960. The increases are, however, most remarkable for women in their twenties, for whom the frequency was less than 30 per 1000 in the early 1960's, increasing to around 60 per 1000 in 1972, that is roughly a doubling. Most of this increase occurred in the last three years.

The trend is quite different for very young women (15-19), where there is at first an increasing frequency, reaching a peak in 1967; after that there is a slight decline and a stabilization at a level approximately 40 per cent above the rate in 1960. Thus, most of the increase in extra-marital fertility is accounted for by women in their twenties.

Figure 2. Extra-marital births per 1000 non-married women.

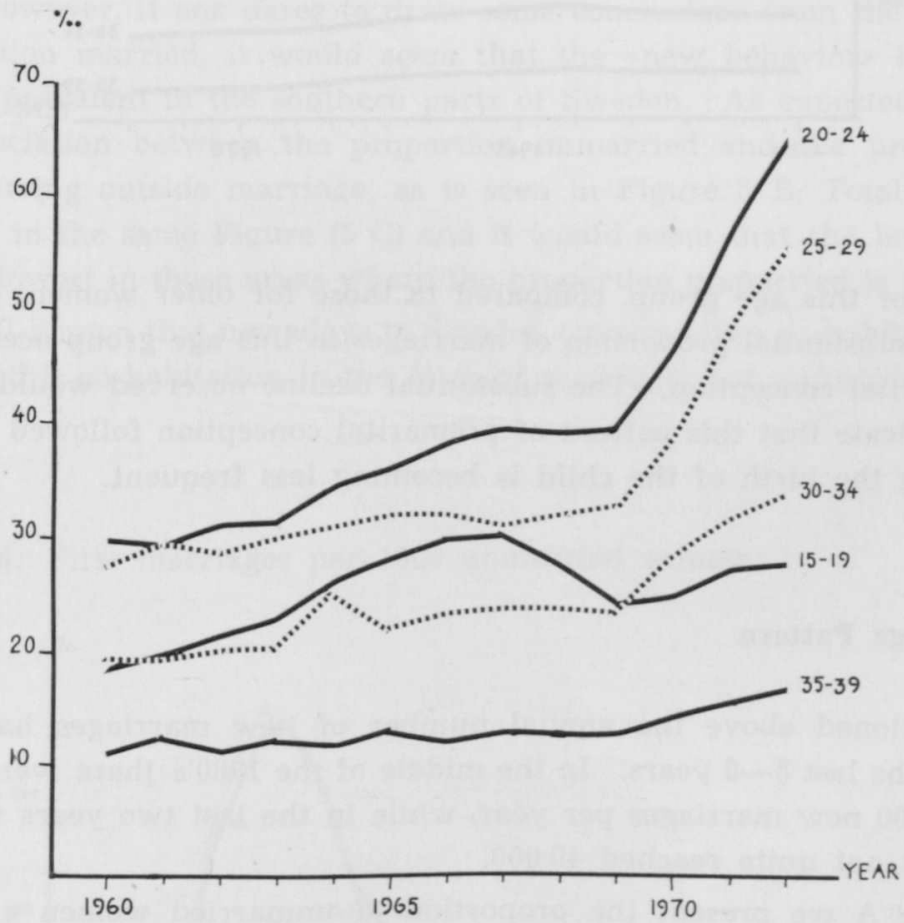

In contrast to these trends, we find that nothing that dramatic has happened to marital fertility (see Figure 3). The most remarkable change in the number of marital births per 1000 married women is the substantial decline observed for very young women. From rates between 500 and 550 in the first half of the 1960 's, there is a very rapid decline and a slight recovery, leading to rates slightly exceeding 400 per 1000 in the early 1970's. Rates are, however, still 
Figure 3. Marital births per 1000 married women.

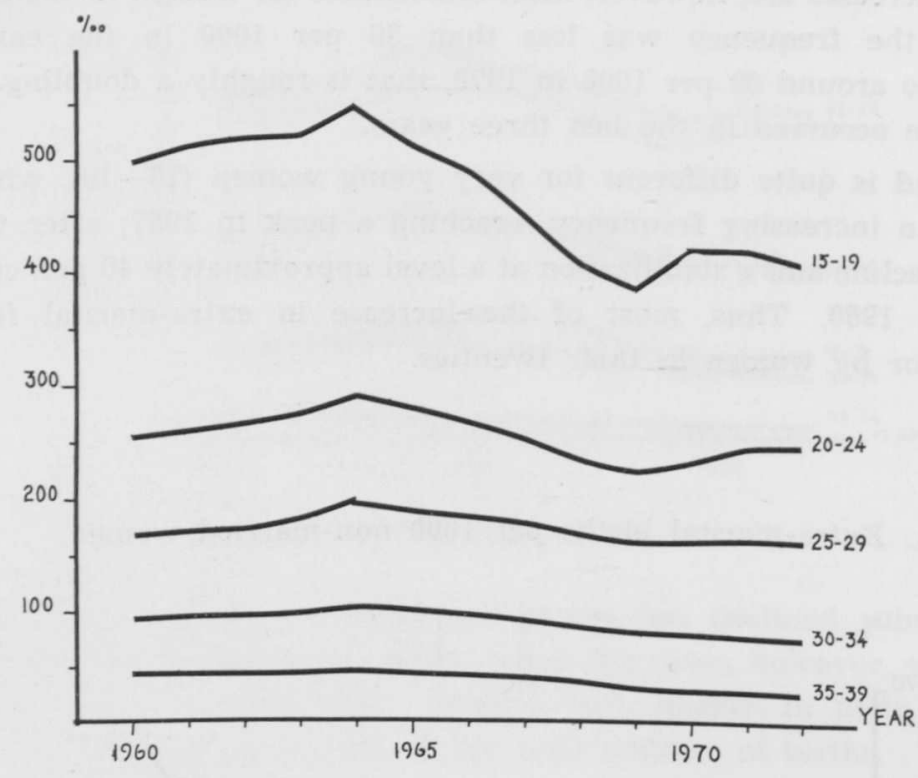

very high for this age group, compared to those for older women, due to the fact that a substantial proportion of marriages in this age group occur because of a premarital conception. The substantial decline observed would, however, seem to indicate that this pattern of premarital conception followed by a marriage before the birth of the child is becoming less frequent.

\section{The Marriage Pattern}

As mentioned above the annual number of new marriages has declined sharply in the last 5-6 years. In the middle of the 1960's there were approximately 60000 new marriages per year, while in the last two years the annual number has not quite reached 40000.

In Table A we present the proportion of unmarried women at different ages during the 1960-1972 period.

The increase in the proportion unmarried is not quite as marked among women who reached 30 years at the end of 1972, but they had already married to a large extent before the onset of the decline in the marriage frequency.

Figure 4 shows the number of first marriages per 1000 unmarried women during the years 1960, 1965 and 1971. There has been a marked decline, affecting all ages, but naturally the youngest, most marriage-prone ages have experienced the largest declines. 
$\mathrm{T}$ a ble A. Proportion unmarried women at different ages.

\begin{tabular}{crrrr} 
Year & \multicolumn{4}{c}{ Age } \\
& 20 & 22 & 25 & 30 \\
1960 & 78.0 & 54.1 & 27.6 & 13.5 \\
1965 & 77.0 & 53.2 & 27.3 & 12.4 \\
1968 & 79.1 & 54.7 & 28.5 & 12.9 \\
1970 & 84.8 & 61.1 & 32.0 & 14.1 \\
1972 & 89.2 & 69.9 & 38.2 & 15.7
\end{tabular}

There are relatively large regional differences in the proportion unmarried women. Figure $5 \mathrm{~A}$ shows the proportion unmarried women in the $20-24$ age group in different provinces at the end of 1971. There were regional differences in the proportion unmarried even before the decline in the number of marriages started. However, if one dares to draw some conclusions from the changes in the proportion married, it would seem that the "new behavior» has not yet become as prevalent in the southern parts of Sweden. As expected there is a strong association between the proportion unmarried and the proportion of births occurring outside marriage, as is seen in Figure 5 B. Total fertility is also shown in the same Figure $(5 \mathrm{C})$ and it would seem that the level of total fertility is lowest in those areas where the proportion unmarried is the highest.

It is well-known that nowadays in Sweden couples often co-habitate without registering this co-habitation in the form of marriage, but unfortunately there

Fig u re 4. First marriages per 1000 unmarried women.

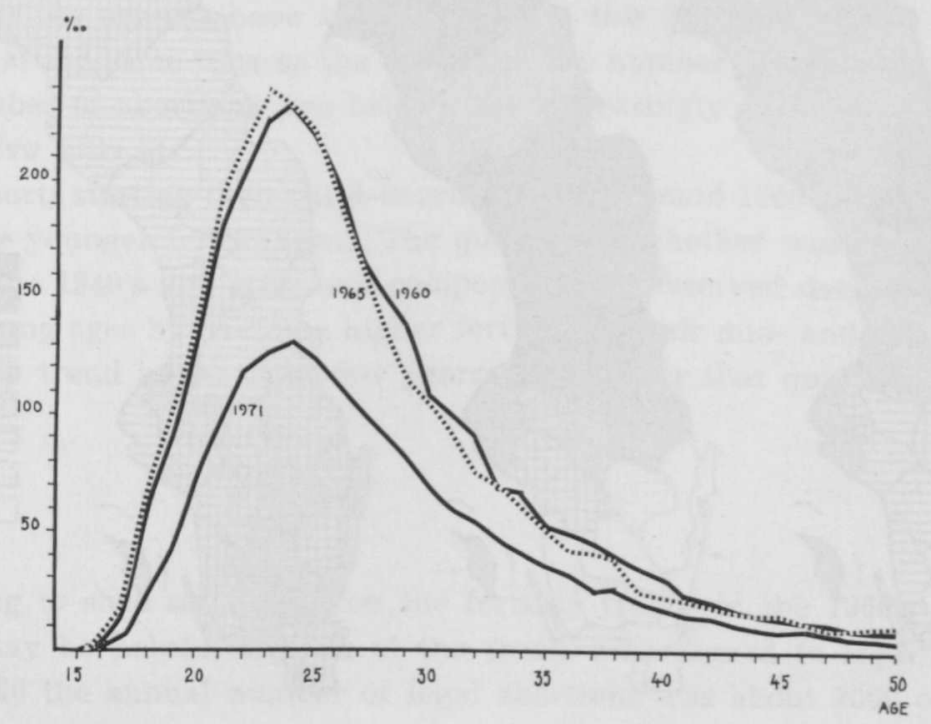


are no statistics that would show how common this "free form» of cohabitation is. In the absence of data on "co-habitation" regardless of marital status, we can only speculate on how common it is. We are inclined to think that the proportion co-habitating (regardless of marital status) has in fact not changed very much in the last few years. It would seem, however, that the new, free form of co-habitation has had a negative effect on the total fertility level (perhaps this co-habitation without being formally married is seen as a period of »trying-out» during which child-bearing is postponed).

\section{Cohort Fertility}

The change in the fertility pattern, which has occurred simultaneously with the decline in the frequency of marriage, comes out very clearly in the fertility behavior of the cohorts.

The previous trend toward earlier child-bearing which is clearly demonstrated in the fertility behavior of cohorts born in the 1920's and 1930's, seems to have come to an end with women born in the middle of the 1940's and

Figure 5. Proportion unmarried women in the $20-24$ age group (A), proportion extra-marital births (B) and total fertility (C), expressed as an index where Sweden $=100$.

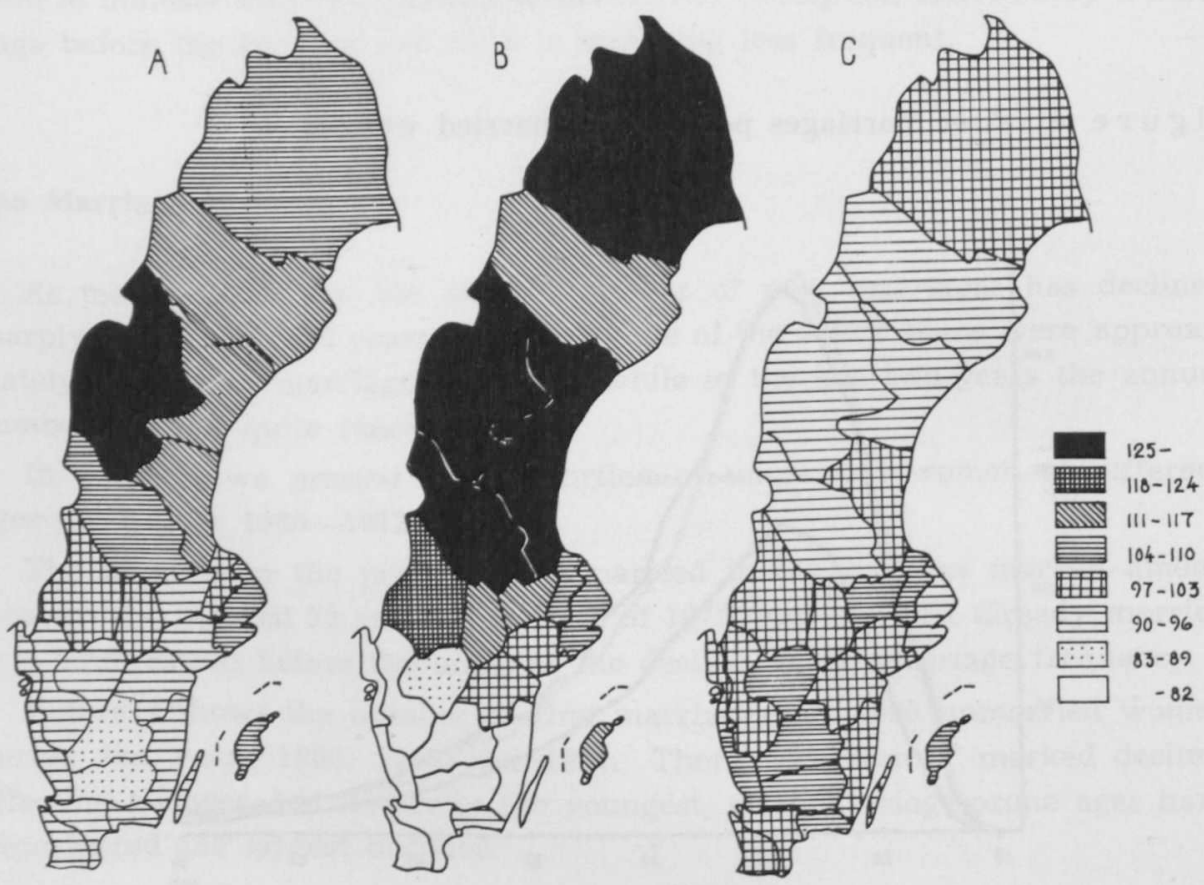


Figure 6. Age-specific fertility rates for cohorts.

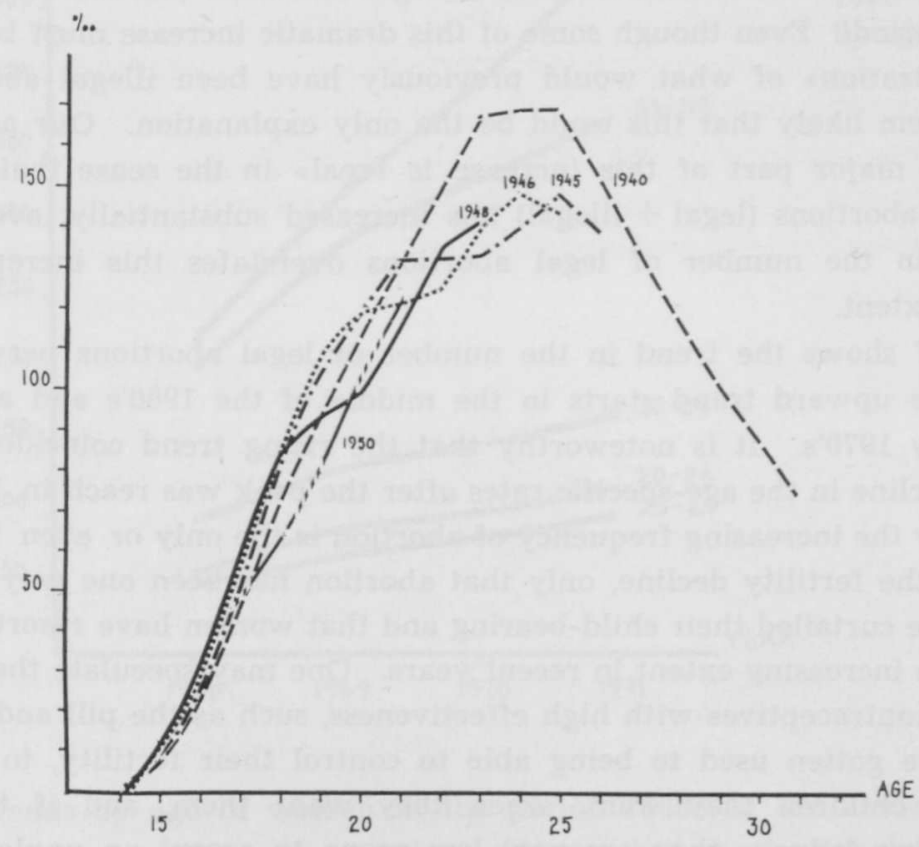

later. These latter cohorts show a fertility behavior that is unique in Sweden's demographic history. The age-specific fertility rates for women born in 1940 and later are shown in Figure 6.

The diagram shows that women born in the middle of the 1940's have high fertility in the younger fertile ages. Suddenly this smooth trend is broken and the curves reach a plateau. The trend is broken at different ages for different cohorts, but the cohorts have in common that this happens around 1968, that is roughly at the same time as the decline in the number of marriages, the rise in the number of abortions (see below), the increasingly widespread use of the contraceptive pills etc.

The cohorts starting their child-bearing period around 1968 have low fertility rates in the younger fertile ages. The question is whether women born in the middle of the 1940's and later will compensate the observed decline in fertility at these young ages by having a higher fertility in their mid- and late twenties. The fertility trend in the next few years will answer that question.

\section{Abortions}

In trying to shed some light on the fertility trends in the 1960's and early 1970 's it may be helpful to look at the trend with regard to legal abortions. Around 1960 the annual number of legal abortions was about 3000 or roughly 
30 abortions per 1000 live births. The preliminary figure for 1972 is 24200 which means that the annual number of legal abortions has increased 8 times over this period! Even though some of this dramatic increase must be a result of a »legalization» of what would previously have been illegal abortions, it does not seem likely that this could be the only explanation. Our assumption is that the major part of this increase is »real» in the sense that the total number of abortions (legal + illegal) has increased substantially, even though the trend in the number of legal abortions overstates this increase to an unknown extent.

Figure 7 shows the trend in the number of legal abortions per 1000 live births. The upward trend starts in the middle of the 1960's and accelerates in the early 1970's. It is noteworthy that the rising trend coincides roughly with the decline in the age-specific rates after the peak was reach in 1964. This is not to say the increasing frequency of abortion is the only or even the major reason for the fertility decline, only that abortion has been one way in which women have curtailed their child-bearing and that women have resorted to this means to an increasing extent in recent years. One may speculate that because of modern contraceptives with high effectiveness, such as the pill and the IUD, women have gotten used to being able to control their fertility, to have the number of children they want, when they want them, and if there is a »contraceptive failure» they are now less prone to accept an unplanned and unwanted child.

It is unfortunately not possible to analyse the trend with regard to different age groups or number of previous births over the whole period, since before 1968 only the number of abortions authorized by two physicians is known. Abortions approved by the Royal Medical Board constitute the overwhelming majority in the earlier years, but only 30 per cent of the abortions performed in 1971.

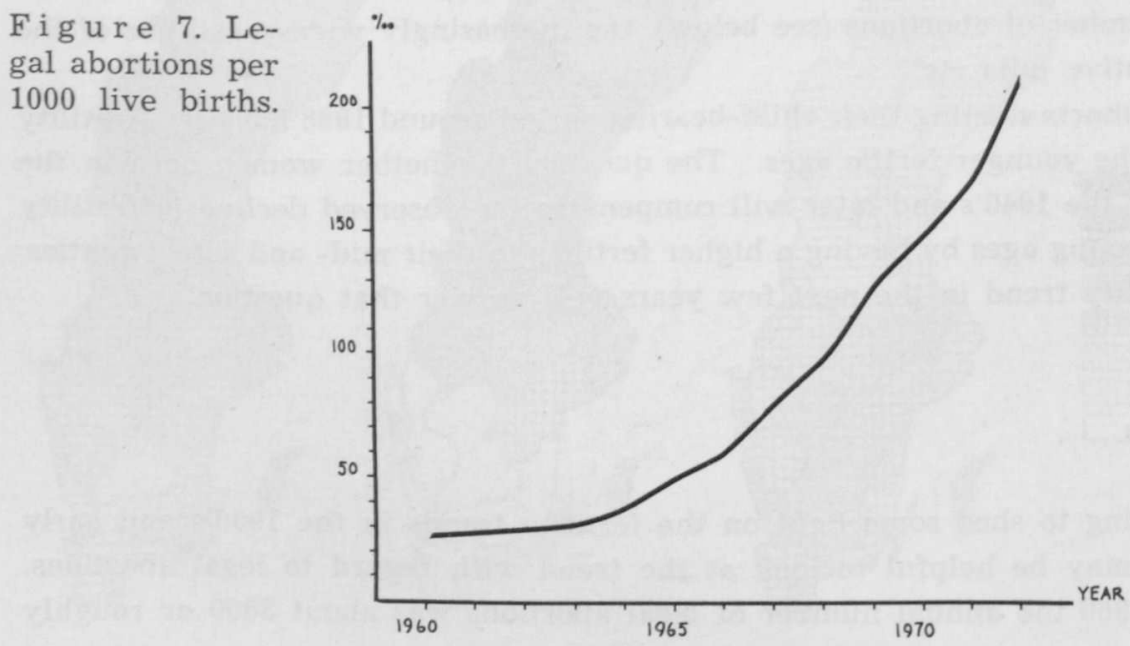




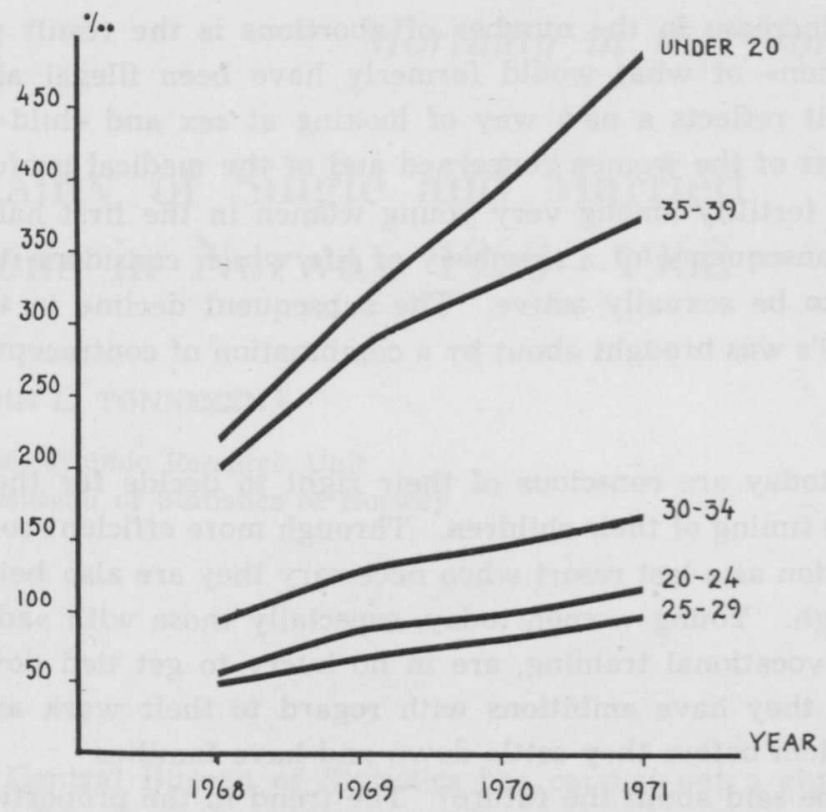

Figure 8. Legal abortions per 1000 live births by age of women.

The trends by age of women in the period 1968-71 are shown in Figure 8. Clearly, increases have occurred at all ages but most remarkably at ages under 20, where the number of legal abortions approaches half the number of live births. In this period the number of legal abortions increased from 11000 to 19000 , that is by 8000 . Three-fourths of this increase is accounted for by women under the age of 30 . In terms of number of already born children, two-thirds of the total increase is due to women with 0,1 or 2 children. In 1970 close to 40 per cent of the women undergoing abortion were childless. All these figures seem to indicate that abortion is increasingly being resorted to by young women who want to postpone the arrival of the first child or lengthen the interval between subsequent births, rather than as the last resort by women who are exhausted by frequent child-bearing in the past in combination with a difficult social and economic situation.

\section{Discussion and Tentative Conclusions}

On the basis of the data presented in this paper we would like to suggest the following hypotheses regarding the present fertility situation in Sweden:

(1) The proportion of couples co-habitating (whether legally married or not) has not changed substantially in recent years despite the decline in the frequency of marriage;

(2) Those couples that co-habitate without being formally married tend on the whole to have fewer children than the formerly married couples, or at least to postpone their child-bearing to more advanced ages; 
(3) The dramatic increase in the number of abortions is the result partially of a »legalization» of what would formerly have been illegal abortions, but primarily it reflects a new way of looking at sex and child-bearing, both on the part of the women concerned and of the medical profession;

(4) The increasing fertility among very young women in the first half of the 1960 's was a consequence of a new way of life which considers it normal for teenagers to be sexually active. The subsequent decline in the later half of the 1960's was brought about by a combination of contraceptive pills and abortions.

Young couples today are conscious of their right to decide for themselves the number and the timing of their children. Through more efficient contraception and with abortion as a last resort when necessary they are also better able to carry this through. Young women today, especially those with "advanced» education or some vocational training, are in no hurry to get tied down with children too early; they have ambitions with regard to their work and want to enjoy some freedom before they settle down and have families.

What then can be said about the future? The trend in the proportion married is very difficult to predict. It will depend on possible changes in the marriage laws, social benefits and rules of taxation, to the extent that such changes favor or disfavor legal marriages versus other forms of co-habitation. Women presently in their younger child-bearing ages would seem to reach a completed fertility of less than two children per woman. 